\title{
Nobel Prize 1994 for Medicine/Physiology
}

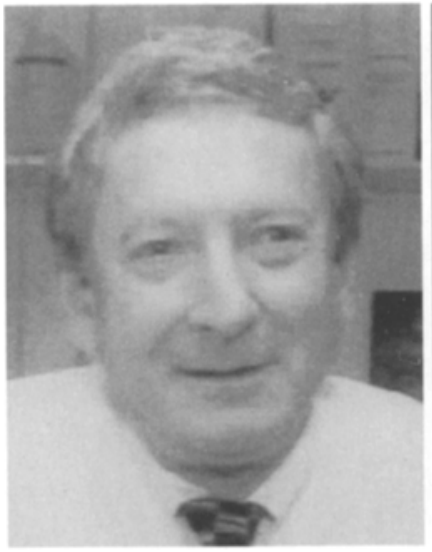

Alfred G. Gilman

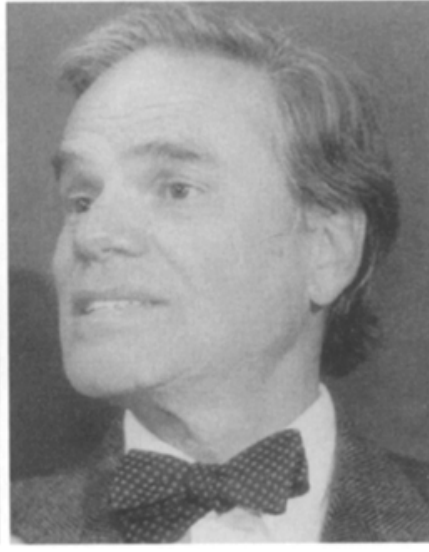

Martin Rodbell

The 1994 Nobel Prize for physiology/medicine was awarded to two American scientists, Alfred G. Gilman and Martin Rodbell, for their work on $G$ proteins.

Numerous laboratories have studied the cellular communications that are necessary for coordinating cellular functions in the organism. Hormones, locally acting autacoids, neurotransmitters, and growth factors all act as extracellular signal molecules. Work on the cellular effects of these hormonal factors began during the 1940s in the laboratory of the 1947 Nobel Prize winners, Carl and Gerty Cori, at Washington University in St. Louis, Missouri. They were seeking to clarify the signal cascades from the receptors involved in regulation of cellular functions. While studying the regulation of liver glycogen phosphorylase, a former associate of the Coris, Earl W. Sutherland, together with his associate Theodore W. Rall, discovered cyclic AMP and established its role as an intracellular signal molecule. Following this discovery, Earl W. Sutherland was awarded the Nobel

G. Schultz

Institut für Pharmakologie, Universitätsklinikum Rudolf Virchow, Freie Universität Berlin, Thielallee 67-73,

D-14195 Berlin, Germany

Prize in 1971. Two colleagues from the Cori laboratory, Edwin G. Krebs and Edmond H. Fischer, known as the "The Two Eds", investigated the muscle phosphorylase system and identified cyclic AMP-dependent protein kinase and established protein phosphorylation and dephosphorylation as a general regulatory principle of protein function. This work resulted in the 1992 Nobel Prize.

By the end of the 1960s Earl W. Sutherland and his associates G. Alan Robison and R. William Butcher had determined that receptors for the catecholamines, adrenaline and noradrenaline, and the regulated enzyme adenylyl cyclase (at that time called adenyl-cyclase) represent domains or subunits of one protein. In 1971 Martin Rodbell and his associate Lutz Birnbaumer at the National Institute of Health in Bethesda, Maryland, reported in a series of ground-breaking publications that the hormonal stimulation of adenylyl cyclase requires GTP and that GTP affects the binding of hormonal agonists to their respective receptor. Rodbell postulated that a GTP regulated "transducer" molecule might be involved between receptor and adenylyl cyclase, at that time the only known effector generating intracellular signal molecules.

By the middle of the 1970s Thomas Pfeuffer, at the laboratory of Ernst Helmreich in Würzburg, separated a GTP-binding protein from the other signal-transducing components, i.e., adenylyl cyclase and receptors. At about the same time Danny Cassel and Zvi Selinger working in Jerusalem showed that hormones stimulate GTP hydrolysis in membrane preparations. At this time Henry Bourne in San Francisco isolated some mutants of S49 lymphoma cells. One of them, called cyc-, became very important in G protein research. Alfred G. Gilman began his career as a doctoral student of Ted Rall in the Pharmacology Department chaired by Earl W. Sutherland at Case Western Reserve University in Cleveland, Ohio. At the University of Virginia in Charlottesville, Virginia, Alfred Gilman was able to show that the S49 cyc- mutant, in which there is no hormonal stimulation of adenylyl cyclase, actually does not have a defect in the adenylyl cyclase but rather in the controlling $G$ protein. 
Using this tool, Al Gilman with his associates John Northup and Paul Sternweis in 1980 accomplished the first complete purification of a regulatory guanine nucleotide-binding protein, i.e., of $\mathrm{G}_{\mathrm{s}}$, the adenylyl cyclasestimulating $G$ protein. During the second half of the 1970s studies by Karl Heinrich Jakobs in Heidelberg and by Martin Rodbell revealed that many hormonal factors inhibit adenylyl cyclase in a GTP-dependent manner, and soon thereafter Al Gilman's laboratory purified the $G$ protein involved, $G_{i}$. They also isolated $G_{0}$ (for "other" $G$ protein) which is now known to be involved in receptormediated inhibition of voltage-dependent calcium channels.

Alfred G. Gilman and his group have provided numerous important contributions elucidating the structure and functions of these and other $G$ proteins involved in signal transduction from receptors to effectors such as adenylyl cyclases and other enzymes as well as ion channels. This three-component signal transduction principle is involved not only in signal transduction processes induced by chemically defined intercellular signals but also in sensory signal transductions induced by light or olfactants. The receptors interacting with $\mathrm{G}$ proteins to induce cellular reactions is presently thought to number about one thousand.

A superfamily of GTP-binding proteins are now known which catalyze GTP hydrolysis and are therefore also called GTPases. These proteins are characterized by their capacity to switch on and off signal-transducing pathways such as regulation of cell proliferation and differentiation, ribosomal protein synthesis, intracellular protein transport, secretion, cell motility, and other important cellular functions. The $G$ proteins, which have also long been called $\mathrm{N}$ proteins (for nucleotide-binding proteins), represent only one subfamily of the GTP-binding proteins. Because $G$ proteins are composed of three subunits $(\alpha, \beta, \gamma)$, they are also designated as heterotrimeric $G$ proteins to distinguish them clearly from low molecular weight or monomeric GTP-binding proteins, for example, ras and related proteins.

Martin Rodbell (age 68), who made early conceptional contributions to G-protein-mediated signal transduction when he worked at the National Institute of Health in Bethesda, Maryland, has recently retired from the National Institute of Environmental Health in Research Triangle Park, North Carolina. Alfred Goodman Gilman (age 53) has been Professor and Chairman for many years at the Department of Pharmacology, Southwestern Medical Center, University of Texas in Dallas, Texas. We can assume that he and his group will provide many more outstanding contributions on the structure and function of $G$ proteins. In addition to his scientific work, $\mathrm{Al}$ Gilman is known as the editor of the concise textbook of pharmacology, Goodman and Gilman's The Pharmacological Basis of Therapeutics, founded by his father, Alfred Gilman, and Louis S. Goodman. 